\title{
Exploration of Flipped Classroom Teaching in College English Based on WeChat Platform
}

\author{
Qi-Qi LIU',a,* \\ ${ }^{1}$ Zhejiang University of Science and Technology \\ Hangzhou, China \\ aqiqi.nancy@163.com \\ *Corresponding author
}

\begin{abstract}
With the reform of teaching theory in recent years, the idea of flipping classroom has gradually been accepted by the Chinese education community and gradually entered our vision. The most important change in flipping the classroom is to change the time inside and outside the classroom and transfer the decision-making ability of learning from teachers to students. Based on the analysis of the characteristics of the flipped classroom and college English teaching, this paper expounds how to realize the concept of flipped classroom by means of Wechat Public Platform and further improve the teaching effect of College English. Finally, through the teaching practice, the above analysis and exploration theory can be realized.
\end{abstract}

Keywords-Flipped Classroom; College English; WeChat Platform

\section{INTRODUCTION}

The flipped classroom came first from Benjamin Bloom's innovative teaching mode that mastered learning theory. It refers to a teaching form in which students use digital materials (videos, electronic textbooks, etc.) produced by teachers to study independently before class, and then participate in the interaction between peers and teachers (answering questions, solving puzzles, exploring, summarizing, etc.) and complete exercises in class. Under this kind of teaching mode, students can concentrate more on active project-based learning, study together to solve the challenges of localization or globalization and other real world problems, so as to gain a deeper understanding. Teachers no longer occupy classroom time to teach information, which requires students to complete autonomous learning before class [1]. They can watch video lectures, listen to podcasts, read enhanced e-books, and discuss with other students on the Internet. They can access the required materials at any time. Teachers can also have more time to communicate with everyone. After class, students plan learning content, learning rhythm, style and presentation of knowledge independently. Teachers use teaching and collaboration methods to meet students' needs and promote their personalized learning. The goal is to make students learn more authentically through practice [2].

Flipping classroom model is a part of the big education movement. It overlaps with mixed learning, inquiry learning, other teaching methods and tools in meaning, all in order to make learning more flexible and active, and to make students participate more strongly. In the Internet era, students learn rich online courses through the internet, so they don't have to go to school to receive teachers' lectures [3]. The Internet, especially the mobile Internet, has spawned the "flip classroom" teaching mode.

\section{ANALYSIS OF THE CHARACTERISTICS OF FLIPPED CLASSROOM}

The earliest "flip classroom" originated in the United States. In 2007, Jonathan Bergmann and Aaron Sams, chemistry teachers at Woodland Park High School in Colorado, USA, began using video software to record PPTs with explanatory voices. The videos they recorded were uploaded to the Internet to make up for missed students. Soon they made a more pioneering attempt - gradually based on students watching videos and listening to lectures at home. In the classroom, teachers mainly conducted problem counseling or provided help to students who had difficulties in doing experiments. And to promote the use of this model in American primary and secondary education. With the development and popularization of the Internet, the method of flipping classroom has gradually become popular and controversial in the United States [4].

According to this teaching method, its characteristics are as follows:

\section{A. Teaching materials are short and incisive.}

Video is the main teaching material in the early flipped classroom. With the development of Internet technology, there are many kinds of teaching materials now. But their common feature is short and vigorous. Most of the teaching materials are only a few minutes, and the longer videos are only ten minutes away. Each teaching material is aimed at a specific problem, has a strong pertinence and is easy to find; the length of video is controlled within the time range of students' attention, which is in line with the characteristics of students' physical and mental development; the teaching material released through the network can be self-controlled, which is conducive to students'self-control. Master learning. 


\section{B. Teaching information is clear.}

The teaching information conveyed by flipping classroom teaching materials is very clear and clear. Take the classic Salman teaching video as an example, the only thing that can be seen in the video is his hand, writing some mathematical symbols constantly, and filling the whole screen slowly. In addition, it is the voice over with the help of writing. In traditional non-flip classroom teaching videos, the frequent appearance of teachers' heads and various objects in the classroom will distract students' attention, especially in the case of students' autonomous learning.

\section{Reconstructing learning process}

Usually, students' learning process consists of two stages: the first stage is "information transmission", which is realized through the interaction between teachers and students, students and students; the second stage is "absorption internalization", which is completed by students themselves after class. Due to the lack of support from teachers and help from peers, the "absorption internalization" stage often frustrates students and loses their motivation and sense of achievement. "Flipped classroom" reconstructs students' learning process. "Information transmission" is carried out by students before class. Teachers not only provide videos, but also provide online counseling; "absorption internalization" is accomplished through interaction in class. Teachers can understand students' learning difficulties in advance, give effective counseling in class, and exchange between students is more conducive to promoting. The process of internalizing students' knowledge.

\section{Feedback testing is fast and convenient.}

After watching the teaching materials, whether the students understand the learning content, followed by four or five small questions, can help students to timely test and make judgments about their learning situation. If some questions are not answered well, the students can look back and think carefully about what has gone wrong. The students' answers to the questions can be collected and processed in time through the technical means of the Internet to help teachers understand the students' learning situation.

\section{AN ANALYSIS OF THE CHARACTERISTICS OF COLLEGE ENGLISH TEACHING}

The new teaching mode of "flip classroom" has entered the teaching field, which provides the development space for the use of new technology, and the new technology also provides a platform for the implementation of "flip classroom". Based on this teaching mode, in the current network environment, practical English teaching should also break through its own limitations, reform classroom teaching, try to use the teaching concept of "flip classroom" in teaching, and use advanced network technology to enrich teaching content. However, it should be noted that the international "flip classroom" teaching mode is not entirely applicable to our teaching system[5]. If the role is not well positioned in the use, it will easily lead to the problem of out-of-place almsgiving relationship. It will not only not differentiate the difficulty of knowledge, but also make the learning content deviate.
Therefore, only on the basis of a real understanding of the connotation of "flip classroom" and a clear understanding of teaching objectives, can we design appropriate teaching models and improve the quality of teaching. Therefore, we also analyze the characteristics of College English Teaching in China [6].

\section{A. Theories and light practice}

In traditional college English teaching, more attention is paid to the cultivation of theoretical knowledge, such as grammar training, the development of various examinations and so on, but the practical work of language competence is relatively weak. There are many reasons for this. One of the main reasons is that the technical means of teaching are not advanced enough.

\section{B. Heavy reading, light listening and speaking}

In ordinary college English teaching, the cultivation of reading ability is the most important. Reading is also the largest proportion of all examinations. However, in modern international exchanges, the cultivation of listening and speaking ability has been paid more and more attention. The solution of these problems can hardly be improved by relying solely on traditional teaching methods.

\section{Students' ability gap is too large}

The enrollment mode of universities determines that students' foreign language abilities vary greatly except for some special majors. Generally speaking, coastal students have strong English ability, especially their application ability, while inland students have poor listening and speaking ability. This gap is difficult to change in the short term. Therefore, under the traditional teaching mode, it is difficult for teachers to carry out individualized teaching for all students in classroom teaching.

These problems can be greatly improved in the mode of flipped classroom. Therefore, it is necessary to carry out the attempt of flipped classroom.

\section{TEACHING PRACTICE BASED ON WECHAT PLATFORM}

As mentioned before, to develop flipped classroom, there must be good technical support. In recent years, with the rapid development of Internet technology, all kinds of "Internet + education" mode has been developing vigorously in the flipped classroom. Among them, the WeChat platform represented by WeChat Public Account is the biggest highlight. Wechat is a mobile social software that can quickly send voice, short message, video, pictures and text through the network to support multi-people chatting. The Wechat Public Account is a one-to-many information push platform based on Wechat. It has high timeliness and rich content of interpersonal communication, which creates a new communication situation. It is popular among young students.

Since September 2015, the author has opened the official Wechat Public Account "Zustdxwyxx" as shown in the screenshot (Fig. 1). Since its inception, it insists on updating the push content every day, which is highly praised by 
teachers and students. Users have high viscidity and high activity. It laid a solid technical foundation for the teaching practice of flipped classroom.

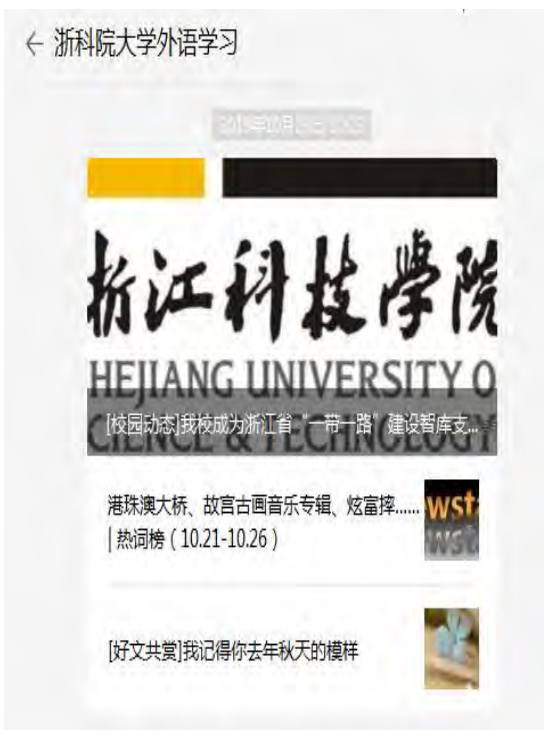

Fig. 1. WeChat Public Account Screenshots

In the process of practice, the author tries to use Wechat Public Account as a platform for the release of classroom teaching materials in some teaching links, and achieves certain results. Take "The Virtual World" as an example, in this course, we should focus on training students' listening and speaking abilities. Therefore, a video was released in advance of the public address. Video content is mainly selected from the US drama "Ready Player One". Screenshots are shown in Fig.2. Prepare students before class and ask questions in the classroom. From the feedback effect after class, we have achieved good results.

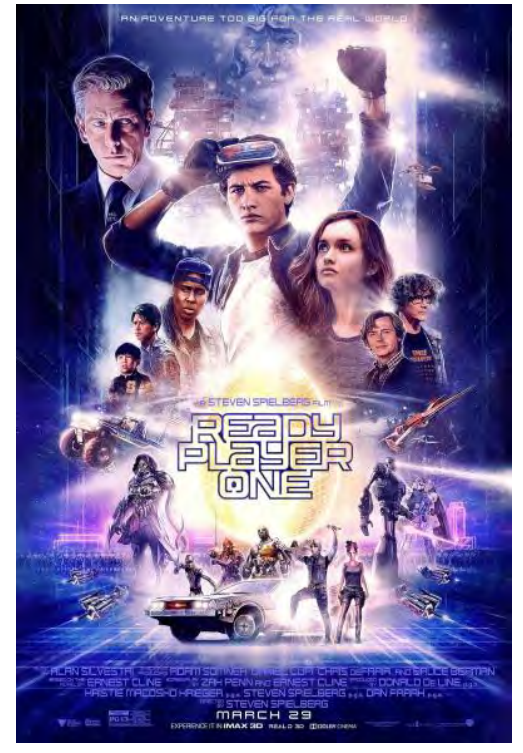

Fig. 2. Ready Player One Screenshots
In the following development process, the author plans to use Wechat Public Account as the core to run the whole platform of flipping classroom teaching resources. The platforms schematic diagram is shown in Fig. 3. The main users include operations management team, teacher users and student users. There is no direct connection between the three, but all through the WeChat Public Account to exchange feedback. The operation management team maintains the public account and manages the upload and operation of the resource server. Teachers and users can upload various teaching resources to the resource server to provide materials for the operation management team. Considering the authority of resources, the resource server will not be opened directly to student users for the time being. In addition to its powerful functions, Wechat Public Signal also has a wealth of external interfaces, which can provide interfaces for a large number of third-party platforms. Therefore, when some special needs functions or Wechat have basic functions but are not rich enough, it can be extended through the third-party platform interface. Through the above platform, we can build an excellent university English flipped classroom platform. The push of teaching resources, the feedback of students'questions, the detection of students' completion, the realization of various questionnaires and the analysis of data, etc., can be realized quickly, accurately, richly and dynamically.

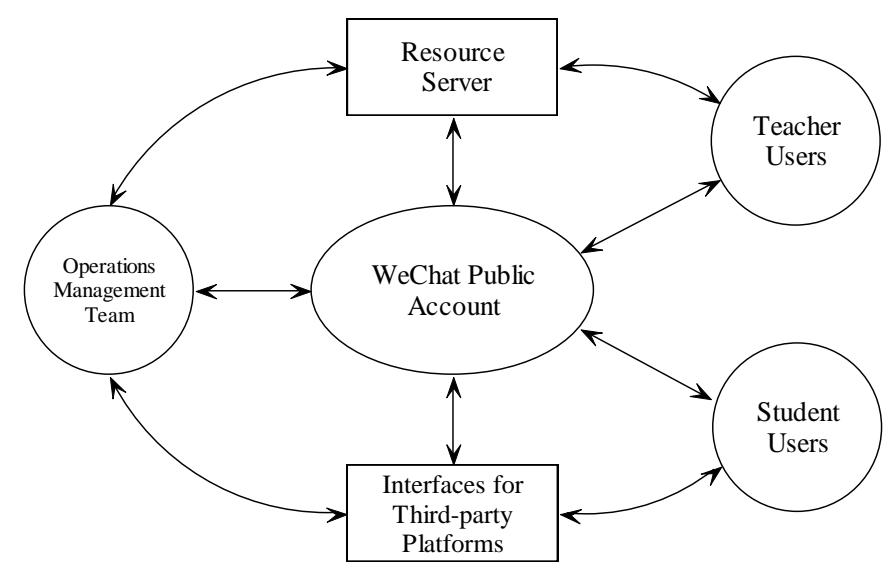

Fig. 3. Schematic diagram of operation platform for flipped classroom

\section{SUMMARY}

To sum up, the author believes that in the reform of the teaching mode of flipping the classroom, can give full play to the role of WeChat technology platform, at the same time to pay attention to the following questions, in order to achieve good results:

\section{A. We must establish a firm belief in teaching reform.}

What kind of educational behavior do we have if we decide what kind of behavior we have and what educational concepts we have? Therefore, if teachers want to be able to carry out the reform of flipped classroom, they must first change their concepts and break their inherent thinking formed over the years. 
B. We must improve our educational informatization level.

There is no doubt that the development of flipped classroom is based on the production of various types of teaching materials. So this also puts forward higher information requirements for teachers. Most College English teachers are not proficient in computer technology because of their liberal arts background, which is also a great challenge to themselves.

\section{Fully understand the essence of flipped classroom.}

More important than teaching materials is how to control the extra time in the classroom. Dialogue and discussion in the classroom, teachers need to make careful preparation and meticulous observation, truly individualized. "Flip the classroom" was successful because the classroom discussion brought by students "assimilation" to enhance the effectiveness of the learning process.

\section{Role transformation}

In the model of flipping classroom, the status of teachers has been weakened to some extent, or more diversified, and become guiders and puzzlers. Students' places are more important and become the main body of learning. Therefore, not only teachers need to change roles, but also students should pay more attention to role transformation.

\section{ACKNOWLEDGEMENT}

This research was financially supported by the Zhejiang Provincial Department of Education Research Project (Y201635360). This paper is a general research project (Y201635360) of Zhejiang Provincial Department of Education.

\section{REFERENCES}

[1] Betul, Aydln, V. Demirer. Flipping the drawbacks of flipped classroom: effective tools and recommendations. Journal of Educational and Instructional Studies, 2016 (2): 33-40.

[2] Armando Fox. From MOOCs to SPOCs. Communications of the ACM, 2013,(12):38-40.

[3] [6] E. Rivera. Using the flipped classroom model in your library instruction course. The Reference Librarian. 56(1): 34-41.

[4] C. N. Li. Application of flipped classroom teaching mode based on WeChat public platform in Higher Education. Chongqing: Chongqing Normal University, 2015. (In Chinese)

[5] Y. J. Zhang. Flipped classroom reform. Information technology education in China, 2012(10): 118-121. (In Chinese)

[6] M. Zhu, Y. P. Wang. Study on the Application of WeChat Public Platform in Public English Flipped Classroom. JOURNAL OF NANTONG VOCATIONAL \& TECHNICAL SHIPPING COLLEGE, 2015, 14(2): 104-107. (In Chinese) 